\section{A Superstructure in Spinels}

IN 1935, E. Kordes ${ }^{1}$ recognized that $\mathrm{LiAl}_{5} \mathrm{O}_{8}$ has nearly a spinel structure, but he observed a large number of extra lines, which he could not explain. A. Hoffman ${ }^{2}$ prepared the corresponding compound $\mathrm{LiFe}_{5} \mathrm{O}_{8}$, which again was recognized as having nearly spinel structure. We found ${ }^{3}$ that the powder diagrams of $\mathrm{LiFe}_{5} \mathrm{O}_{8}$ correspond with a primitive cubic lattice with a lattice constant of $8 \cdot 33 \mathrm{~A}$. The space group was found to be very probably $P_{4} 3$ (or $P 4_{1} 3$ ) and the positions of the atoms (in the notation of the International Tables, 1935) are :

$$
\begin{aligned}
& P 4_{3} 3 \quad 4 \mathrm{Li} \text { at } 4(6) \\
& 12 \mathrm{Fe}, 12(d) \text { with } x=\frac{8}{8}+\Delta_{1} \\
& 8 \mathrm{Fe}, \quad 8(c),, x=0+\Delta_{2}
\end{aligned}
$$

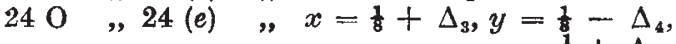

$$
\begin{aligned}
& 80,, \quad 8(c) \quad, \quad x=\frac{8}{8}+\Delta_{6} \\
& z=\frac{1}{8}+\Delta_{5}
\end{aligned}
$$

with $\Delta_{3}, \Delta_{4}, \Delta_{5}$ and $\Delta_{6}$ approximately 0.007 and $\Delta_{1}$ and $\Delta_{2}$ still smaller.

For all $\Delta$ 's equal to 0 , this would mean an ideal spinel lattice with an ordered arrangement of lithium and iron ions in the ratio $1: 3$ over the octahedral sites. The type of the order is best described by considering only the sixteen octahedral interstices. These are occupied by four lithium and twelve iron ions in such a way that each lithium ion is surrounded by six iron ions in an octahedron elongated along a trigonal axis and each iron ion by four iron and two lithium ions.

Single crystals of $\mathrm{LiFe}_{5} \mathrm{O}_{8}$ have been grown and investigated and the above deductions are fully confirmed.

Below $735^{\circ} \mathrm{C}$. the four lithium ions are distributed in this ordered way over the sixteen octahedral interstices. The long-range order decreases only very slowly up to this temperature. Above $755^{\circ} \mathrm{C}$. the long-range order has completely disappeared and the four lithium ions are distributed over the sixteen octahedral interstices only. Up to at least $1,000^{\circ} \mathrm{C}$. they do not enter to an appreciable extent into the tetrahedral interstices.

Between $735^{\circ}$ and $755^{\circ}$ there exists a transition region where the equilibrium long-range order vanishes within a temperature-range of a few degrees. The transition velocity above $755^{\circ} \mathrm{C}$. and below $735^{\circ} \mathrm{C}$. (down to $450^{\circ} \mathrm{C}$.) is very high (transition within a few seconds to a minute). Between $735^{\circ}$ and $755^{\circ}$ there exists a region where the transition to the equilibrium is extremely slow. By rapid quenching from $950^{\circ} \mathrm{C}$. we obtained the disordered phase at room temperature.

$\mathrm{LiAl}_{5} \mathrm{O}_{8}$ shows the same type of superstructure, but the order-disorder transition takes place at much higher temperature. We obtained the disordered phase by quenching from $1,350^{\circ} \mathrm{C}$.

Some specimens of $\gamma \mathrm{Fe}_{2} \mathrm{O}_{3}$, prepared by $\mathrm{E}$. W. Gorter of this laboratory, gave very nearly the same diagrams as $\mathrm{LiFe}_{5} \mathrm{O}_{8}$. They proved to contain some water molecules. In these $\mathrm{\gamma Fe}_{2} \mathrm{O}_{3}$ specimens the type of ordered structure described for $\mathrm{LiFe}_{5} \mathrm{O}_{8}$ is present. which in the ideal case would require a ratio of $1: 3$ for the ordering elements. In the description of $\gamma \mathrm{Fe}_{2} \mathrm{O}_{3}$ as a spinel with vacancies ${ }^{4}, \mathrm{Fe}_{8}\left(\mathrm{Fe}_{1^{2} / 8} \Delta_{2^{2} / 8}\right) \mathrm{O}_{32}$, the ratio of vacancies to iron ions at the octahedral interstices would be at most $1: 5$. The ratio ideal for ordering would be reached by incorporating water molecules, approaching the formula $\mathrm{HFe}_{5} \mathrm{O}_{8}$ as a limiting formula.
Recently, Houben ${ }^{5}$ has shown by absorption measurements that the compound $\mathrm{HAl}_{6} \mathrm{O}_{8}$ also exists under certain conditions. As shown by Ervin ${ }^{6}$, the transition from boehmite to $\alpha \mathrm{Al}_{2} \mathrm{O}_{3}$ and goethite to $\alpha \mathrm{Fe}_{2} \mathrm{O}_{3}$ through the $\gamma$ oxides can be regarded as a gradual rearrangement of the aluminium and iron ions in the cubic close-packed oxygen framework. Since the products of the first transition steps are only nearly anhydrous, the very mobile protons might be expected to play an important part in these transformations. In special cases such as the $\gamma^{\mathrm{Fe}_{2} \mathrm{O}_{3}}$ preparations mentioned, they can even give rise to a highly ordered superstructure in the $\gamma \mathrm{Fe}_{2} \mathrm{O}_{3}$ phase, thus showing that they are not merely present as absorbed water.

\section{P. B. Braun}

Philips Research Laboratories,

N.V. Philips' Gloeilampenfabrieken, Eindhoven. June 13.

${ }^{1}$ Kordes, E., Z. Krist., A, 91, 193 (1935)

${ }^{2}$ Hoffiman, A., Naturw., 26, 431 (1938).

${ }^{3}$ Braun, P. B., paper at ASXRFD meeting, Ithaca, 1949. Van Santen J. H., de Boer, F., and Verwey, E. J. W., J. Chem. Phys., 18, 103: (1950).

4Verwey, E. J. W., Z. Krist., A, 91, 317 (1935). Hägg, G., Z. phys. Chem., B, 29, 88 (1935). Kordes, E., Z. Krist., A, 91, 193 (1935) 5 Houben, G. M. M., thesis, Delft (1951)

- Ervin, Gav, Acta Cryst., 103 (1952).

\section{Crystal Distortion of Graphite in Cast Irons}

ReCentuy, Debye-Scherrer line-breadths, the parameters of unit cells and the proportions of $\alpha$-and $\beta$-modification of graphite present in cast irons, have been published by W. S. Owen and B. G. Street ${ }^{1}$. In connexion with this and other work, I have investigated the variation of disordered structure within a graphite grain by removing, step by step, outer layers of the grains by an oxidizing agent, since the variation seems to exist if we consider the crystal growth of irons.

The graphite samples used were a coarse flake graphite in a commercial grey cast iron, and a temper graphite in a commercial black-heart malleable cast irun of pipe fittings. The graphites were extracted from the cast irons by dissolving with hot dilute hydrochloric acid and washing with hydrofluoric acid. Then the outer layer of the grains was dissolved by wet oxidization. Many examples are known ${ }^{2}$ of penetration of foreign atoms between the layer planes of the graphite crystal by the action of liquid agents ; this results in the increase of the lattice parameter normal to the layer planes. In the present treatment it is necessary that the oxidizing agent should attack gently and uniformly over the grain surface without destroying inner structure. For this purpose, the samples were boiled in an 8 per cent solution of potassium dichromate mixed with sulphuric acid (sp. gr., 1.29) in a flask fitted with a reflux condenser. The grain size of the powder gradually decreased as the boiling continued; after $12 \mathrm{hr}$. in the case of the flake graphite, most of the grains became hexagonal in shape or fragments of hexagons, although the initial shape was irregular and only in rare cases were hexagonal figures observed on the grain surface.

The Debye-Scherrer patterns of these specimens were obtained by using copper $K \propto$ rays and a camera 